\title{
Where is planning to be found? Material practices and the multiple spaces of planning
}

Article

Accepted Version

Allmendinger, P., Haughton, G. and Shepherd, E. (2016) Where is planning to be found? Material practices and the multiple spaces of planning. Environment and Planning C: Government and Policy, 34 (1). pp. 38-51. ISSN 1472-3425 doi: https://doi.org/10.1177/0263774X15614178 Available at https://centaur.reading.ac.uk/68440/

It is advisable to refer to the publisher's version if you intend to cite from the work. See Guidance on citing.

To link to this article DOI: http://dx.doi.org/10.1177/0263774X15614178

Publisher: Sage

All outputs in CentAUR are protected by Intellectual Property Rights law, including copyright law. Copyright and IPR is retained by the creators or other copyright holders. Terms and conditions for use of this material are defined in the End User Agreement.

www.reading.ac.uk/centaur 
Central Archive at the University of Reading

Reading's research outputs online 
Accepted version, Authors' post-print version.

\author{
Allmendinger, P, Haughton G and Sheppard E. Accepted for \\ Environment and Planning $C$ on 17.7.2014.
}

\begin{abstract}
Where is planning to be found? Material practices and the multiple spaces of planning.
\end{abstract}

\begin{abstract}
.
A range of new spaces of English planning have emerged in recent years. One new space of clear import is the sub-region. In this paper we seek to gain a better understanding of why sub-regional spaces emerge, how they are used and how planning functions through them. Drawing upon an analysis of three English regions and interviews with actors the paper identifies four types of sub-regional planning that highlight the relationship between accountable, legally sanctioned territorial spaces on the one hand and more informal, open and strategic sub-regional spaces on the other. Sub-regional planning provides an important if not critical strategic parallel to regulatory planning though the relationship between the two is characterised by complexity, contestation, experimentation and impermanence. Among other issues raised by this contemporary reworking of planning is the emergence of an accountability gap through the uncoupling of formal democratic processes embedded within territories and the more diffuse practices of strategic plan making.
\end{abstract}


A 'region' is normally in a state of becoming, assembling, connecting up, centring, and distributing all kind of things. Yet it has not been always there: it has been constructed and will probably eventually disappear...

The key questions therefore remain to be resolved through abstractions and concrete research: who or what 'constructs' regions and borders, and how, through what associations/networks, and for what purposes? (Paasi 2010, pp. 2299 and 2301)

\section{Introduction}

There has been a recent and growing interest in the emergence of new spaces of planning as part of a wider debate about how we might best understand the processes of regionalisation. Drawing on work on assemblages and the need to build a better understanding of the interplay of territorial and relational perspectives of space (McCann and Ward 2011, 2012, Jones et al. 2013), in this paper we seek to develop a deeper understanding of the new spaces of planning in England through an engagement with material planning practices, exploring: why they emerge, how they are used, and how the regulatory and the positive dimensions of planning are now achieved through such spaces. In the process we address some of the questions raised by Paasi in our opening quote, demonstrating how certain types of region-building might involve different balances between the discursive and material practices through which new regions emerge (Allen et al. 2007, Allen and Cochrane 2010, Jessop 2012a, 2012b).

To do this we focus upon what we see as a planning scale of growing import in English spatial planning, what can loosely be called the subregioni. The sub-region, understood here as a space of planning smaller than a standard English region but larger than a typical local authority, has a chequered history. At various times its importance has been emphasised if not privileged, while at other times sub-regional spaces 
have been de-emphasised as part of the ebb and flow of planning reform (Roberts and Baker 2004, Buser and Farthing 2011). However, the sub-region has always exerted a gravitational-like pull on planning practitioners, even at times when such spaces did not form part of the official pantheon of statutory planning spaces and scales.

Yet it would be misleading to suggest that the sub-region is replacing other planning spaces for two reasons. First, there are and always have been complex accretions of scales and spaces of planning to which the emerging significance of sub-regions are adding. Second, as far as material practices of planning are concerned there are distinct spaces related to its many potential functions. The English planning system comprises a complex ensemble of such practices and functions - statutory, regulatory, visionary, consultative, analytical, administrative and political. The two main functions of planning - planmaking and regulatory planning - reflect the separation of 'plan' from 'permission' in the English system, each of which, as we go on to discuss, can conceive of and work through different spaces. Our findings suggest that the new spaces of planning around the sub-region principally reflect the plan-making functions of planning whilst the regulatory, 'permission' functions remain solidly anchored to the realm of territorial spaces ${ }^{\mathrm{ii}}$.

In addition, the research presented here reveals how the new practices of sub-regional planning are essentially pragmatic exercises in ensuring plans are produced in effective ways rather than visionary exercises in place-making. Under such a pragmatic agenda, the necessities of performing the required bureaucratic functions, the material practices of planning, dominate over the task of attempting to engage with the public and other stakeholders in seeking to develop and popularise more ambitious sub-regional imaginaries.

In the next section we discuss some fundamental characteristics of the material practices of planning (notably its regulatory instruments, including the production of agreed plans and strategies) and the 
relationship to space before setting out how sub-regional spaces of planning in three English regions have been assembled and constitute new locales and spaces for practice. To help inform this discussion, 28 interviews were undertaken during 2013 (see below). Finally, we reflect upon such the implications of such practices for understanding contemporary planning dynamics.

\section{Space and Planning}

The 'relational turn' in geography from the early 2000s sought to develop new way of thinking about space and scale as unbounded geographies and local nodal interactions of global flows (Amin, 2004; Massey, 2005). This shift in thinking quickly fed into planning debates (Healey, 2007; Davoudi and Strange, 2009; Paasi 2013). In response to a perceived over-privileging of relational over territorial spaces in parts of this literature there has been a reappraisal of the territorialrelational dichotomy (Jones, 2009; Cochrane, 2012; Goodwin, 2012) alongside thinking about how space and place, the global and the local, are assembled (McCann and Ward, 2011). According to this latter view spaces are assemblages, both open, internally heterogeneous, constituted through a myriad of connections and networks and territorially institutionalised objects, the outcome of various 'political' contestations and struggles' (Ward and McCann, 2009: 171; see also Massey, 2011; Cochrane, 2012; Jones, 2009; 2011). Central to this conceptualisation of the relationship between space and policy-making is its openness, best summarised as a "global-relational process, social and spatial process which interconnects and constitutes actors, institutions and territories" (McCann and Ward 2012, p.328).

From the perspective of planning practice such understandings of space as assemblages of the territorial and the relational, the global and the local, provide a useful starting point from which to engage with the changing nature of planning spaces. To paraphrase Ward and McCann (2009: 168) in this paper we aim to provide a concrete or empirical engagement within this understanding to help 'uncover' how spaces and policy in the form of new, sub-regional planning spaces are 
assembled, emphasising the multiplicity, openness and over-layering of spaces and practices, rather than privileging one particular approach to making and animating sub-regional identities and practices.

There are three broad dimensions that need to be accommodated into a refined policy assemblage approach for planning: how assemblage thinking relates to the different functions of planning; how the variable 'permanence' of planning spaces needs to be accounted for and, finally, an appreciation of how new planning spaces can be used in progressive and less progressive ways. We now deal with each of these in turn.

The practices of planning involve a range of functions as highlighted above, though two core roles stand out. One function is to 'think ahead' and plan in the broadest, future orientated, policy sense (the positive), a function that requires both 'opening up' and 'closing down'. Planners working on the positive function within legally defined territorial spaces need to engage with and take on board extra-territorial inputs and factors which can be either spatial or nonspatial. A significant influence on such considerations is national government planning policy, which currently encompasses a wide range of objectives including a statutory purpose for planning in contributing to the achievement of sustainable development (DCLG, 2012: para 6). What constitutes 'sustainable development' is to some extent left open, echoing the current Coalition government's ethos of 'localism' or the idea that the scope and purpose of planning are best determined locally. Further, those working on statutory plans seek to coordinate their work with other policy sectors as well as private actors and interests that work through different territorial and relational spaces, 'reaching out' to colonise, coordinate with and mobilise other policy sectors, plans and strategies and places to achieve effect. Yet such, 'opening' and relational thinking needs to be subsequently 'closed down' into a single plan or strategy for a particular territory. 
The second main function is linked to the first and involves a more responsive, legal role of allocating rights in order to implement or execute the plan (the regulatory) to determine and allocate property rights, i.e., planning permission. Here, the plan takes on a different role moving from being the product of an 'open', visioning process to being a material input into a statutory process where there will be 'winners' and 'losers'. So the first pertinent characteristic is that planning works with different conceptions of space depending upon the function and that such conceptions sit 'side-by-side', i.e., a plan needs to be both relational and territorial.

This brings us to the second relevant characteristic around the duration or 'permanence' of different spaces, as Jones (2009) puts it. Territorial spaces are not only distinct from relational spaces in their characteristics of openness and 'closed-ness', for example, but also in terms of their permanence. Whilst some have characterised territorial spaces as 'temporary permanences,' existing as nodal moments or temporary constellations within ever-changing often far-reaching flows and networks (Massey 2005, Agnew, 2005), such impermanence is itself relative. There have been periodic reorganisations of some territorial spaces though such changes are rare ${ }^{\mathrm{iii}}$. The territorial spaces of local government for instance are typically fairly stable. On the other hand the region, in the English case, has an unstable existence particularly from the perspective of planning (e.g., Allen and Cochrane, 2010; Allmendinger and Haughton, 2010). In other words the choice of space and scale has, perhaps, helped shape the view of space as always becoming, 'constantly in the process of emerging, disappearing and reemerging' (Ward and McCann, 2009: 171).

This resonates strongly with those who argue that attempts to develop new regional identities do not emerge seamlessly; rather they are subject to interruptions, reversals, contestations and all too often they simply falter and fade (Paasi 2010, 2013, Jessop 2012a, 2012b, Metzger, 2013). It is important to emphasise here that some policy spaces are more stable and enduring than others. As far as planning is 
concerned its primary space of material practice is that of local government, with its relatively enduring nature and permanence. However, this same characteristic of relative fixity can in some cases be interpreted as an 'obstacle' that needs to be negotiated by planning authorities seeking to engage better with more 'open' and relational spaces and practices. It is in this context that 'spatial planning', with its emphasis on strategic, visionary and extraterritorial forms of thinking, has helped justify the creation of new planning spaces alongside, through and within the enduring, territorially dominant space of the local. Such informal or soft spaces are not subject to the same vacillation as formal or hard spaces. Neither are they subject to the same transparency and accountability.

So, following from this, our third characteristic of planning concerns recent practices that draw upon both formal, institutional or 'hard', territorially dominated spaces, and spatial practices and informal, fuzzy and 'soft' spaces that speak to more open and relational concerns. Those working on such soft spaces typically engage with more relational ways of thinking and are open to experimentation with unusual geographies and less bounded notions of what a subregion might look like when thinking of, for instance, functional economies, environmental policies or housing markets (Deas and Lord, 2007; Haughton et al., 2010; Heley 2013). The key point here is that though important and relatively enduring, territorial spaces constitute only one dimension of contemporary planning practice. The creation and use of new, non-territorial planning spaces can be seen as being within the broad remit of planning practice as described above - a temporary, 'open', 'spatial fix' - but this would be to overlook the other uses to which such spaces can and have been put. In the case of planning, these new arrangements can be used to displace politics away from the democratic arrangements of statutory local government planning in order to more easily facilitate growth and neutralise opposition (Allmendinger and Haughton 2010, Haughton et al., 2013). 
These characteristics of planning highlight how planning practices have long adopted and adapted to the challenges of space and scale, balancing territorial and relational spaces, the need to rely upon jurisdictional powers and fulfil legal obligations with the diffusing power of networks above and beyond places and nations. Such adaption is possible because of the considerable discretion built into English planning to manage the territorial and relational. One consequence of these three characteristics and the considerable discretion is that in any assessment of space as a material practice attention should be focused upon the struggle for space and how multiple factors such as national discourses and policy contexts (e.g., competiveness, growth, sustainability, etc.), professional cultures (e.g., regulation and positive), identities and spatial imaginaries are interpreted, negotiated and contested within relatively enduring legal and institutional territorial contexts. One such new planning space in England is the sub-region, a space of and scale for planning that reflects the tensions between the territorial and the relational and helps us better understand how planning spaces are assembled - and how these processes have helped produce more diverse practices than perhaps has been previously recognised.

\section{Assembling the sub-region}

There has been considerable interest in developing new sub-regional forms of planning since the early 2000s, in part reflecting the faltering progress of the regional project under New Labour, particularly after the failed referendum on introducing elected regional government in the North East of England, plus lobbying on behalf of city regions by the influential Core Cities group (ODPM 2006). Whilst not ceding ground on its regional level ambitions for planning and economic development, in 2008 the Labour Government began to acknowledge the significance of sub-regional planning for housing and growth delivery and improved economic efficiency and productivity, requiring better sub-regional co-operation and decision making between local 
authorities and their partners (DCLG, 2008: 4). The conclusion from government guidance at the time was that 'there is a clear conceptual as well as practical rationale for planning policy to be developed at sub-regional level' (DLCG, 2008: 36). This entreaty to think subregionally largely mirrored planning practices that had for some time looked to identifying functional planning areas beyond the territorial boundaries of cities, such as housing market areas (Haughton, et al., 2010, Hincks and Baker 2013).

The plea to act and think sub-regionally, effectively creating new spaces of planning, sat alongside the formal, territorial spaces and responsibilities of local, regional and national planning. There would be no formal reorganisation of territorial planning to accomplish this change. Instead there was an emphasis on local actors coming together in novel formations, sometimes within the apparatus of regional planning, sometimes driven by economic development partnerships at regional, sub-regional and city-regional scales, for instance, with cityregions particularly prominent in this debate (Harrison 2012).

In 2010 the election of a Coalition government led to a radically altered sub-national governance apparatus, as the regional scale of planning and economic development was quickly dismantled, amidst claims that it was ineffective, bureaucratic and not adequately accountable to local people (Allmendinger and Haughton 2012, 2013, Pugalis and Townsend 2013). Under the broad banner of 'localism', more powers in areas such as planning and economic development were to be pushed to the local and neighbourhood scale, albeit not necessarily with more resources given the parallel policy drive to reduce public expenditure. Recognising concerns that the abandonment of the regional strategic level left a large 'gap' between local and national government, the Coalition government engaged in a series of initiatives to 'fill the gap' in ways that might broadly be thought of as sub-regional. In planning, local authorities were given a new duty to cooperate with other 'prescribed bodies', including 
adjacent local authorities (The Town and Country Planning (Local Planning) (England) Regulations 2012 (SI 2012/767) r.4).

The Duty to Cooperate was introduced by the Localism Act 2011 and reinforced in planning policy at paras $178-181$ of the National Planning Policy Framework. It was cited in many of our interviews as a factor in the emergence or strengthening of existing patterns of closer cooperation and partnership between adjacent local authorities. A key driver in this process has been how the Planning Inspectorate has been interpreting the Duty. By 2013 the Inspectorate had questioned a number of proposed local plans on the grounds of unclear cooperation between authorities, leading all planning authorities to realise that the new duty would need to be taken seriously rather than simply treated as a 'tick box' exercise (Hogger, 2013; Kingaby, 2013). As such the Duty to Cooperate has emerged as a key driver in the strengthening of some sub-regional planning arrangements and in the creation of new ones.

Paralleling this duty in the field of economic development the government encouraged local actors to create Local Economic Partnerships (LEPs), leaving local partnerships to determine their own geographies provided that these operated at a scale above that of local government. The result was a new network of sometimes over-lapping institutions led by private sector actors that are not yet specifically mandated to cover planning issues, but which planning authorities are expected to consult with in drawing up their plans. In practice it has been left to individual LEPs to explore for themselves their areas of focus, with central government determined not to impose a singular template on LEPs, potentially leading to quite substantial variations in practice, though initially at least limited funding and staffing thwarted any expansionary intentions in most LEPs (Pugalis and Townsend 2013). In some cases LEPs chose to brand themselves as city regional (e.g. Liverpool and Leeds), typically adding a level of formality and policy crystallisation to the earlier city-region scale partnerships. 
There have been substantial other moves since 2010 to take forward city-regional governance arrangements. The most formal arrangement is currently the Greater Manchester Combined Authority (GMCA), established in 2011(Sandford, 2013: 3-4). The GMCA now has statutory powers to improve cooperation between the 10 constituent local authorities in economic development, regeneration and transport. This formalises a long-standing city-regional scale of activity, most evident in the activities of the Association of Greater Manchester Authorities (AGMA), which covers 10 constituent local authorities. AGMA emerged following the decision by central government to dismantle the elected Greater Manchester County Council in 1986 and has been active ever since in attempting to provide a level of sub-regional policy coordination in planning and other policy areas. In effect GMCA and AGMA now co-exist, with AGMA taking forward city-regional scale cooperation in non-statutory policy areas. There are concrete plans to create a further three Combined Authorities for Greater Merseyside (DCLG, 2013a), West Yorkshire (DCLG, 2013b) and Durham, Northumberland and Tyne and Wear (DCLG, 2013c).

City Deals are a parallel example of the policy 'hardening' of the sub-regional agenda around England's cities to varying degrees. City Deals are agreements directly made between central government and local actors, operating at the city-regional scale involving new powers and mutual commitments. The first round of City Deals was made in 2012 between central government and the eight core cities (seven 'city-regions' and Nottingham), with a further 20 announced in the following year. Each deal was bespoke, but the overall agenda was to devolve powers and tools to the cities to help 'drive local economic growth' and 'unlock projects or initiatives that will boost... economies' (HM Government, 2012: 1). Each Deal is expected to include strengthened governance arrangements to address the opportunities and challenges of cross-boundary working. The bespoke nature of each agreement allows for policy innovation to emerge and with this an asymmetry in the new powers involved, with some areas more involved 
for instance in transport infrastructure issues than others. For the government:

'city deals are not a 'one time' event but a continuing process. Over the months and years ahead, the core cities will need to make the most of these new powers and projects; show that local power and initiative can and does work; and come back to Government to negotiate greater powers and freedoms' (ibid, p.3).

In effect then we have seen the creation of various new city regional governance and partnership arrangements, from LEPs and City Deals through to Combined Authorities. These only started to be developed after 2009 and each has a slightly different purpose, although there is considerable overlap. The result is a potentially complex network of governance arrangements. What is interesting and significant about this movement is that whilst the broad direction of policy is being set by central government, there is an ideological aversion to rolling out a common blueprint for the emerging new institutions and a predisposition to encourage local actors to work out for themselves the geographies and the functional scope of the new sub-regional institutions they have been invited to create. This means there is no set template for how these spaces might relate their activities to the planning system, and there is certainly no central government guidance for what sub-regional planning might consist of or even for whether it is needed in every area. The resulting institutional landscape for sub-regional planning is therefore both varied and largely unknown.

With this in mind our research set out to better understand the evolving nature of sub-regional planning spaces. Three standard regions were chosen to explore these issues: East Anglia, the East Midlands and the South West. An initial desk-based review of all potential examples of cross-administrative boundary cooperation by local authorities and other organisations was carried out. This involved reviewing every local authority and county council website in each of 
the three regions in order to determine whether the authorities in question were working with other administrative or planning entities in any respect, taking account of varying degrees of formality. Based on this initial review, a number of potential cross-administrative boundary partnership types with corresponding examples were identified, operating with varying degrees of formality. We then conducted interviews with 28 key actors from each of the partnership types that we identified, between May and December 2013. Initially there were more partnership types identified, including ones relating to legacy arrangements for Local Strategic Partnerships and Thames Gateway partnership areas, but as these are now largely advisory or consultative and mainly of diminishing direct input into planning we focus here on the four main types of sub-regional planning arrangements that emerged from this review process.

Conjoint Planning Spaces. This category of sub-regional planning comprises formal joint partnerships between two or more territorial authorities and their jurisdictional spaces in which statutory plan making powers have been fused resulting in the ability to jointly adopt the same planning documents. Such partnerships may have separate public identities and branding to the authorities comprising them. This said, they were not associated with high profile efforts to 'brand' a new planning space, rather they were more titled in fairly prosaic fashion to denote their limited ambitions. Examples of this type of approach included the South East Lincolnshire Joint Strategic Planning Unit and the Central Lincolnshire Joint Strategic Planning Unit.

The precise organisational and administrative pooling arrangements for the various partnership types in this category differ, but they share the following essential features:

i. They have a joint committee capable of adopting joint planning policy documents. 
ii. Such joint planning policy tends to be strategic in nature with other, less strategic planning documents produced at local level.

iii. The constituent authorities produce joint evidence base documents.

iv. Development management powers may remain vested in the separate local authorities, with development management decisions made by separate planning committees at local level. This is the case for the two examples we contacted for interview.

Although there are currently no set time limits for these partnerships, they may be temporary and provisional upon political support and alignment. While the powers to create joint plans and form joint planning committees were introduced by s 28 and s 29 Planning and Compulsory Purchase Act 2004, the partnerships we spoke with were formed relatively recently, with the oldest formed in 2009.

The reasons given for the formation of these partnerships included cost savings and efficiency, geographical positioning of the partnered authorities, a previous culture of working in partnership linked to the regional spatial strategies and the fact that administrative boundaries were getting in the way of making decisions in the context of areas which had begun to function as sub-regional economic spaces in practice.

Aligned Policy Spaces. This category of sub-regional planning spaces comprises territorial authorities that are cooperating in some 'aligned' planning policy outputs, but statutory plan making functions remain separate.

As with Conjoint Planning Spaces, the precise organisational and administrative pooling arrangements for the various partnership types in this category differ. There may be more formal aligned planning 
policy units comprising officers from the separate councils working together, or a less formal arrangement in which the policy units are separate but their work coordinated. The policy output also differs: whereas some partnerships may produce separate planning policy documents that are closely aligned with each other, others may work together to produce a single aligned document. However, in each case the policy would have to go to separate planning committees at local level in order to be adopted separately. This is the key distinction from Conjoint Planning Spaces.

Whilst some areas producing such aligned documents refer to them as 'joint' planning policy documents, we refer to them here as 'aligned' so as to distinguish them from planning policy which has been adopted at a single joint committee.

The reasons given for partnering in this way included costs saving and efficiency, coordination leading to more efficient use of resources and local authorities having already had a history of working together. Although the National Planning Policy Framework specifically encourages the production of joint planning policies on strategic matters (DCLG, 2012: 42-43), where we encountered it, cooperation on the production of aligned planning policy tended to pre-date the removal of the regional spatial strategies as the powers to do so were introduced in the PCPA 2004. Examples include a long history of cooperation in the south west on gypsy and traveller sites, whilst EU Habitats regulations were cited by an interviewee as being a key driver of the production of Dorset Heathland Joint Development Plan Document, work that has its roots dating back to a 2007 joint planning framework.

Reasons given by interviewees for not partnering up in a more formal way included a lack of political will, 'arduous' bureaucratic hurdles, and a lack of need in the case of a partnership involving just two local authorities. However, indication was given that in time at 
least some of the aligned policy spaces may progress towards more formal arrangements.

One recent trend that broadly fits it with the 'aligned policy' category has been the 'shared services' agenda, a process that began from about 2011 in response to the need to make cost savings and deliver greater efficiencies. Suffolk is a good example of this, with all the district and borough authorities in Suffolk now sharing chief executives, except Ipswich. The partnered authorities are Suffolk Coastal and Waveney, Babergh and Mid Suffolk and Forest Heath and Edmundsbury, each at different stages of merging their corporate management teams and departments. This has now started to feed into planning. For example, Babergh and Mid Suffolk have a joint development management team and a joint planning policy team. The policy team has started to produce a common evidence base and an aligned Development Management Policies Development Plan Document, although it will go to separate committees for adoption.

Local Enterprise Partnerships. The shift from 2008 to favour substate economic policies and spaces led to the embryonic emergence of business-led LEPs in 2010 as new, locally determined areas for the coordination of growth related policies and investment across the public and private sectors. While LEPs do not themselves as yet have formal plan making powers, local planning authorities have a duty to cooperate with LEPs and have regard to LEPs when preparing plans. As previous noted, the LEP model encourages a variety of approaches and underpinning philosophies. Further, there is clearly a move to enhance the role and significance of LEPs, particularly following the Heseltine Review (Heseltine 2012).

The Chancellor's autumn statement in November 2012 announced funding for LEPs as part of their responsibility to draw up Strategic Economic Plans, with the strength of plans then determining how much central funding would be devolved to them including funding for transport and housing. One of the criteria that the government will use 
to determine the strength of the plan and how much funding will be devolved is the extent to which they coordinate land use planning and align adopted local plans.

The need for LEPs to prepare Strategic Economic Plans inevitably prompts questions about to what extent they are now engaging in a more formal kind of sub-regional planning. One interviewee at a LEP suggested that “you can't really get into a meaningful local economic growth strategy without really getting into strategic planning and being aware of population forecast, demographic change, housing numbers and strategies etc., and while you wouldn't expect a local economic growth strategy to repeat the structure plans or the regional spatial strategies, it must be aware of the wider aspects". Another interviewee at a LEP described the way in which "LEP responsibilities have grown exponentially" since their inception and following the Heseltine Review "so that they've grown beyond what we envisaged they would do which, you know, is a good or bad thing depending on what your view of LEPs' capabilities are".

A third interviewee at a LEP said: "the LEP began in many senses as being almost...very averse to getting involved in that kind of territory [spatial planning] because of the political sensitivity of it.... For the LEP to begin drawing a quasi-regional plan was, you know, totally off the agenda". However, the interviewee went on to say that there could potentially be a "greater spatial dimension" to the LEP's work "such as the spatial identification of potential key employment sites for example". The interviewee concluded: "If the direction of travel from those who are currently responsible for spatial planning, if they wish to collaborate within the LEP infrastructure then fine, I am sure we would... but we have no ambitions to do that, nor plans."

We can begin to see from this range of responses that there has been an expansion in LEP powers which may in time bring them into conflict or alignment with statutory planning powers at local level. For the time being, the nature of this relationship remains open, creating 
the space for localised experimentation to take place if local actors decide this is something they wish to pursue.

Joint Evidence Base Arrangements. Where there is a mismatch between territorial and functional planning spaces then adjoining authorities can prepare joint evidence base documents to underpin work on strategic planning. This type of joint work on evidence base documents is well established as a result of the Local Development Framework system introduced after 2004.

Examples include housing market, housing land, retail catchment or travel to work areas that extend across a number of authorities. When preparing individual plans authorities can jointly commission evidencebased documents generally on a joint methodology, though interpretation and plan making may remain the responsibility of the authority itself. There are several rationales for this kind of work. Firstly it can help reduce costs through sharing the work of developing an evidence base either in-house or through commissioning consultants. Secondly, it makes sense to share the work where there are strongly over-lapping functional housing market or labour market areas in particular. In addition, since the Duty to Cooperate came into force they have been a useful way of demonstrating to planning inspectors that adjoining planning authorities have worked together in producing their plans.

Although a joint evidence base may have been produced by those authorities involved in other sub-regional planning arrangements, a separate category is warranted for those authorities that only produce a joint evidence base and do not engage in producing aligned or joint planning policy documents.

It is also worth emphasising here the role of Strategic Housing Partnerships, which are typically arranged on functional housing geographies. Though they have no direct planning role in practice they can support planning work on housing issues and may help to 
coordinate activity and produce a housing joint evidence base in terms of the Strategic Housing Market Assessment and Strategic Housing Land Availability Assessment.

\section{Reflections on the emerging practices of sub-regional planning}

There has always been some level of informal, spatial or nonterritorial dimension to planning with authorities working across boundaries to cooperate and create functional planning areas or coordinate land use policy on issues of collective concern. This flexibility has been a key feature of the discretionary UK based planning approach. Yet the changes in the nature of planning space over the past decade or so mark a step-change in such ad hoc and bespoke arrangements (Haughton, et al., 2010). Compared to twenty years ago the current landscape of plans and planning is more complex and multi-sectoral, overlapping and evolving, multiple and diverse in the approaches.

The research presented here derives from a review of the partnership arrangements in three English standard regions; it cannot therefore claim to present an exhaustive description of the entire range of different sub-regional partnerships. We know, for instance, of the private-sector led model of the Atlantic Gateway in the North West, which has no parallel in our case study regions.

Nevertheless, our research does point to the existence of a range of sub-regional planning spaces and practices. In part this variety reflects a continuation from how sub-regional matters were dealt with under New Labour, for instance the 2004 arrangements for Regional Spatial Strategies encouraged the use of sub-regional thinking particularly for sub-regions that crossed over the boundaries of the formal regions. In practice, many RSSs also used sub-regions as building blocks for their broader strategies, for instance in Yorkshire and the Humber (Haughton et al. 2010). But it is also important to emphasise that since 
the Coalition government chose to close down regional planning and to encourage greater devolution of powers to city-regions, there has been a growing diversity of practices evident as demonstrated in the softeredged Local Enterprise Partnerships and in more recent moves towards harder and more formally aligned planning spaces under the 'shared services' agenda

Our review of how these arrangements are developing provides a number of pointers to how sub-regional planning has evolved in the recent period. Firstly, when looking at all the arrangements in total in any region we can see how they are product of a complex accretion of and interaction between different planning spaces. Or to put it another way, new sub-regional spaces emerge into a congested and complex landscape, meaning that other competing forms of subregional arrangements may well co-exist and in effect be competing for government powers and resources. This governance multiplicity can be thought of as the new marketplace for spatial governance. If former systems of government tended to be hierarchical and ordered with a rhetorical political emphasis on reducing duplication, in the new governance systems multiplicity and overlap are now seen as not simply acceptable but as positive features that encourage growth. National governments are not simply spatially strategic and selective in their preferred scales for allocating new resources and responsibilities, increasingly it seems they wish to see a range of governance types at any scale vying with each other to get access to government powers. For the Coalition government, there is an ideological commitment to fostering diversity and experimentation. The downside of this is that there is little sense of commitment to longevity for any of the emerging arrangements, which has then pre-disposed those running them to focus more on achieving pragmatic outcomes around plan preparation rather than the more tricky issues of region-building often associated with creating new planning spaces in the past.

Secondly, we can see how despite their continuing existence after many years of uneven policy support sub-regional planning spaces 
remain in an ambiguous position, between the jurisdictional, democratically accountable territorial spaces of local authorities and the national spaces of policy guidance and advice of government and ministers.

The outcome of such evolutionary complexity and ambiguity could well be reflective of a state of disorder, a lack of coherence to governance institutions and structures and the emergence of an evolutionary, 'primordial soup' of spatial opportunities and possibilities: a struggle for space. Alternatively, this complexity and ambiguity could also reflect the growing potential for flexibility and relative freedom to establish governance arrangements and a variety of sub-regional planning regimes which at least seek to be more responsive to local need and the perceived realities of economic areas rather than purely administrative ones.

For all the seeming instability facing individual partnerships, at the system level the rise of informal, coalitions and partnerships in subregional planning may help reduce risk and increase certainty for strategic planning in an area, since more informal, bottom-up partnerships are likely to prove more resilient to the whims of central government. If this is indeed one outcome this may help contribute to longer-term certainty of the kind that developers so often call for and which governments pay lip-service to even as they engage in yet another round of planning restructuring.

What has also become clear from the research is that different subregional spaces fulfil different roles and have different characteristics suited to those roles - so LEPs for instance are very different in scope and function to conjoint planning arrangements. These varied functions and characteristics allow those involved in making and remaking new institutional landscapes for planning in effect to 'pick and choose' between alternatives, and if none look suitable, to start again with a new type of planning space. 
Finally, it is worth 'closing the loop' and reflecting upon an underlying theme of this paper outlined earlier around how contemporary planning delivers the two traditional functions of regulation and positive planning and what role the new, sub-regional spaces play in this. The traditional, silo-based approach to the regulatory and the positive in planning has now clearly dissipated. The regulatory has in all cases remained tethered to the territorial spaces of local authorities whilst the positive - including the inputs into regulatory decision making - have in some cases been separated and opened up more to wider influences.

\section{Conclusions}

This research demonstrates that the majority of sub-regional planning initiatives have tended to be focused on pragmatic behaviours, sharing data and analytical functions, producing agreed strategies, working together to achieve cost-savings in plan production, meeting governmental expectations for consulting with neighbouring planning authorities. Such behaviours are not solely an English phenomenon (see Zimmerbauer and Paasi, 2013). These are the new material practices that are defining sub-regional planning in England today, aimed at minds rather than the heart of a grateful populous, far from the utopian visionary planning once associated with trying to create new sub-regional plans, such as the estuary plans of the 1960s and 1970s (Frey 1971, Glasson and Marshall 2007). They are also far from the rich set of diverse processes identified in some of the academic literature as being important to explaining the emergence of new regional economic imaginaries (Jessop 2012b).

This is not to say that the sub-regional planning practices of the present are reduced to a shadow of former practices or that they lack imagination, but rather to say that they are aspirational in different ways. The sub-regional planning initiatives identified by our research would probably all aspire to playing a role in ensuring that the planning 
system produces good quality plans and strategies even in the reduced circumstances that most local authorities find themselves in the face of financial cuts as part of the national government's austerity drive. It is not the kind of planning associated with the great planning seers, such as Ebenezer Howard or Patrick Abercrombie, but it is too early to write it off as unlikely to produce powerful new plans that actually deliver on their promises. It is for this reason that sub-regional planning practices merit further critical investigation. Whilst they are could be interpreted as pragmatic technocratic exercises rather than as creating new sub-regional spaces, but such a view might mask some very real changes in strategic thinking about an area's future development.

At a more abstract level we can interpret the proliferation and complexity of new, sub-regional planning spaces as assemblages between the local and the global, the territorial and relational. But we would argue that that these assemblages also emerge out of wider set of ideological debates about how to do governance and the role of the state in the current era of fiscal austerity. Planning is important in this as a form of regulatory practice that all western governments accept as an essential function, even as they face continuous pressures to reform planning to fit with the latest trends in neoliberal thinking about the appropriate role of the state in regulating markets. The result is a series of on-going reforms about the practices and spaces of planning, in which the discourses of austerity and market-facing policy are important drivers in encouraging policy makers to make planning more effective, more accountable to local people, and less costly.

Planning practice in turn is riven with the need to be simultaneously territorial and relational, regulatory and positive. And this situation is clearly dynamic with some spaces emerging and taking on new significance whilst others fade in import. The familiar nature of contemporary English planning masks some important changes in how its regulatory and positive aspects are currently being reworked. The previous alignment of both functions onto territories has been 
disrupted. There is now a separation of the regulatory, which still sits clearly within territorial spaces, and the positive, which has expanded into new spaces.

Finally, it is worth reflecting upon the implications of such a separation of the positive and regulatory on transparency and accountability and return to the title of this paper - where is planning to be found? The disruption of alignment between territories and planning functions also severs the link between planning and its legitimacy through democratic processes and procedures. From a practical perspective this can mean that engaging in plan making becomes fraught given the mismatch between the territorial and relational spaces of planning: where is planning to be found? Whilst this may be viewed as an inevitable consequence of managing the tensions between the positive and the regulatory from another perspective such a fuzzying of accountability can help in growth delivery through reducing engagement, input and opposition (Allmendinger and Haughton, 2012).

This paper reveals how sub-regional planning is continuously being assembled and reassembled not in neutral fashion, as part of some natural rhythms of governance restructuring. As Paasi $(2010,2013)$ begins to intimate, the processes of assembling the sub-region reflect a complex, underlying geographical political economy about how the state steers the restructuring of sub-national governance, involving a mixture of political, pragmatic and bureaucratic rationales. The role of local level experimentation in governmental forms and behaviours is simultaneously a form of cooptation and liberation in allowing discretion in how these processes of assemblage and search for legitimacy are constructed. Local actors are indeed shaping their own destinies, to a degree, and if successful they can hope to continue to be allowed to embed and evolve. But at another level, there are external pressures driving the rules of the new market for spatial governance, and out of the interplay of local experimentation will emerge new arrays of winners and losers, in terms of governance 
bodies but also, potentially, sub-regional growth prospects. To conclude, our research suggests that assemblage thinking is helpful in understanding the restructuring of planning, but that this always needs a parallel emphasis on the role of political economy. 


\section{References.}

Agnew, J. (2005) Space: place. In Cloke, P. and Johnston, R.J., editors, Spaces of geographical thought, London: Sage, 81-96.

Allen, J. and Cochrane, A. (2010) Assemblages of state power: topological shifts in the organization of government and politics, Antipode, 42:5, pp. 1071-1089.

Allmendinger, P. and Haughton, G. (2010) Spatial Planning, Devolution and New Planning Spaces, Environment and Planning C, 28: 803818

Allmendinger P and Haughton G (2012) Postpolitical spatial planning in England: a crisis of consensus? Transactions, Institute of British Geographers, 37: 89-103.

Allmendinger $P$ and Haughton $G$ (2013) The Evolution and Trajectories of English Neoliberal Spatial Governance: 'neoliberal' episodes in planning, Planning Practice and Research, 28.1, 6-26.

Amin A, 2004, "Regions unbound. Towards a new politics of place" Geografiska Annaler B 86(1) 33-44

Brenner, N, Madden DJ and Wachsmuth D (2011) "Assemblage urbanism and the challenges of critical urban theory," CITY, 15.2, 225-240.

Buser M and Farthing S (2011) Spatial Planning as an Integrative Mechanism: A Study of Sub-regional Planning in South Hampshire, England, Planning Practice and Research 26.3,307-324

Cochrane, A. (2012) Making up a region: the rise and fall of the 'South East of England' as a political territory, Environment and Planning C: Government and Policy, 30: 95-108

Davoudi S, Strange I, (2009)"Space and place in twentieth century planning: an analytical framework and an historical overview", in Conceptions of Space and Place in Strategic Spatial Planning Eds S Davoudi, I Strange (Routledge, London) pp.7-42

Deas, I and Lord A (2006) "From a new regionalism to an unusual regionalism? The emergence of non-standard regional spaces and 
lessons for the territorial reorganisation of the state." Urban Studies 43.10, 1847-1877.

Department of Communities and Local Government (DCLG) (2008)

Planning and Optimal Geographical Levels for Economic Decision Making - the Sub-Regional Role, HMSO, London

Department of Communities and Local Government (DCLG) (2012)

National Planning Policy Framework, HMSO, London

Department of Communities and Local Government (DCLG) (2013a)

Proposal to establish a combined authority for Greater

Merseyside Consultation, HMSO, London

Department of Communities and Local Government (DCLG) (2013b)

Proposal to establish a combined authority for the area of West

Yorkshire Consultation, HMSO, London

Department of Communities and Local Government (DCLG) (2013c)

Proposal to establish a combined authority for the area of

Durham, Northumberland and Tyne and Wear Consultation, HMSO, London

Frey, A.E. (1971) Estuary Development Feasibility: Tayside,

Humberside and Severnside Compared. Area 3.4, 231-33.

Goodwin M A, 2012, "Regions, Territories and Relationality: Exploring the Regional Dimensions of Political Practice" Regional Studies

Harrison, J (2012) Life after regions? The evolution of city-regionalism in England, Regional Studies, 46, 1243-1259

Haughton G, Allmendinger P, Counsell D and Vigar G (2010) The New Spatial Planning: territorial management with soft spaces and fuzzy boundaries, Routledge, London.

Haughton G, Allmendinger P and Oosterlynck, S. (2013), Spaces of

neoliberal experimentation: soft spaces, postpolitics and neoliberal governmentality, Environment and Planning A, 45 (1) 217-234.

Healey, P. (2007) Urban Complexity and Spatial Strategies: Towards a Relational Planning for Our Times (London: Routledge).

Heley, J. (2013), Soft Spaces, Fuzzy Boundaries and Spatial Governance in Post-devolution Wales. International Journal of Urban and Regional Research, 37: 1325-1348. 
Heseltine, M. (2012) No stone unturned (London: BIS).

Hincks, S. and Baker. M. (2013) Housing Market Areas and the Strategic Planning of Housing in England, Town Planning Review 84.1, 127152

HM Government (2012). Unlocking growth in cities: city deals - wave 1. Cabinet Office, London.

Hogger, D., 2013. Letter to Mid-Sussex District Council, http: / /www.midsussex.gov.uk/media/ID-16DTCOConclusion.pdf [accessed 13th March 2014].

Jessop B (2012a) Economic and ecological crises: green new deals and

no-growth economies' Development 55(1), 17-24

Jessop B (2012b) Cultural Political Economy, spatial imaginaries,

Regional Economic Dynamics, CPERC Working Paper, 2012-2.

Lancaster University: Available,

http://www.lancaster.ac.uk/cperc/docs/Jessop\%20CPERC\%20Wo rking\%20Paper\%202012-02.pdf

Jones, M. (2009) Phase space: geography, relational thinking, and

beyond. Progress in Human Geography 33 (4), 487-506.

Jones, L., Mann, R. and Heley, J. (2013) Doing space relationally:

Exploring the meaningful geographies of local government in

Wales, Geoforum 45: 190-200

Kingaby, J., 2013. Letter to Rushcliffe Borough Council.

http://corestrategy.rushcliffe.gov.uk/media/Rushcliffe/Media/D ocuments/PDF/Newsandpromotions/Rushcliffe\%20Core\%20Strateg y\%20exploratory\%20note.pdf [accessed 13th March 2014]. Massey, D. (2005) For Space. Sage, London.

Massey, D. (2011) A Counterhegemonic Relationality of Space. In E. McCann and K. Ward (eds), Mobile Urbanism: Cities and Policy Making in the Global Age, University of Minnesota Press, Minneapolis, MN.

McCann, E., Ward K. (2011) "Introduction." In Mobile Urbanism, ed. McCann, E., Ward, K, Minneapolis: Minnesota University Press. McCann, E. \& Ward, K. (2012) Policy assemblages, mobilities and mutations: Toward a multidisciplinary conversation. Political Studies Review, 10(3), 325-332.

Metzger, J. (2013), Raising the Regional Leviathan: A RelationalMaterialist Conceptualization of Regions-in-Becoming as Publics- 
in-Stabilization. International Journal of Urban and Regional Research, 37: 1368-1395

Metzger J, Schmitt P, 2012, "When soft spaces harden: the EU strategy for the Baltic Sea Region” Environment and Planning A 44 263280

Office of the Deputy Prime Minister (ODPM) (2006). A framework for City-Regions. ODPM: London

Paasi, A. (2010) Commentary. Regions are social constructs, but who or what 'constructs' them? Agency in question. Environment and Planning A 42.10, 2296-2301.

Paasi A, 2013, "Regional planning and the mobilization of "regional identity": from bounded spaces to relational complexity" Regional Studies, 47.8, 106-1219. dx.doi.org/10.1080/00343404.2012.661410

Pugalis, L and Townsend, A (2013) Rescaling of planning and its interface with economic development. Planning Practice and Research, 28.1, 104-121.

Thomas K and Roberts P (2000) Metropolitan Strategic Planning in England: strategies in transition, Town Planning Review 71.1, 25Ward, K., McCann, E. "Conclusion." In Mobile Urbanism: cities and policy-making in a global age, ed. McCann, E., Ward, K, Minneapolis: Minnesota University Press, 2011.

Zimmerbauer, $\mathrm{K}$ and Paasi, A. (2013) When old and new regionalism collide. De-institutionalization of regions and resistance identity in municipality amalgamations, Journal of Rural Studies 30, 31-40

\footnotetext{
${ }^{i}$ Here we are referring to sub-regions as being functional spaces at a scale lower than the recently abolished regions though, as one of the referees rightly points out, there sub-regions may also be seen as new forms of region.

ii However, note the cooperative and even joint development control functions created by some authorities such as Cambridge City and South Cambridgeshire District Councils for sites adjacent to or even crossing administrative boundaries. iii As pointed out by one of the referees local authority spaces are not fixed and could be seen as enduring, relational spaces rather than fixed, territorial spaces.
} 